\title{
Coarticulation of Nasal Vowels in Monguor Language
}

\author{
Zhang Hanbin \\ NLIT Department, School of Foreign Languages \\ Northwest Minzu University \\ Lanzhou, China \\ zhanghb06@163.com
}

\begin{abstract}
The purpose of the study is to discuss the coarticulation of nasal vowels in Monguor language. On the base of acoustic parameter database of the Monguor speech, the study discusses the differences in the coarticulatory dispersions between the nasal vowels $[\tilde{a}]$ and $[\tilde{\tilde{z}}]$ and the locus equation slopes of the unaspirated stops by the following nasal vowels $[\tilde{a}]$ and $[\tilde{\mathbf{j}}]$. The results show that, in Monguor language, the coarticulatory

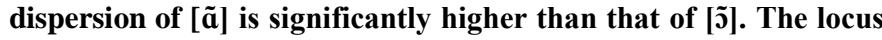
of the bilabial or apical, but not for the velar, unaspirated stops can be calculated by means of the locus equation. The slope of the velar is the highest, and that of the apical is the lowest.
\end{abstract}

Keywords-Dispersion; Locus equation; Coarticulation; Monguor

\section{INTRODUCTION}

Coarticulation is the way the pronunciation of a certain sequence of vowels and consonants is produced, and the individual movements needed for each will be interwoven into one smooth whole. That is to say, these individual articulator movements which are necessary for adjacent vowels and consonants are produced skillfully, smoothly and simultaneously. As a result, special acoustic information about a vowel or consonant can be spread out in coarticulation.

The studies on coarticulation of nasal vowels in English vary. Vowel nasalization from the standpoint of prosodic strengthening is a coarticulatory process which can factually be fine-tuned by speakers (e.g. Cho, 2016[1]; T. Cho, D. Kim, \& S. Kim, 2017[2]). The effects of prominence and boundary on vowel nasalization in CVN and NVC structures show that prominence brings out coarticulatory resistance and enhances the vowel's orality; boundary brings out anticipatory coarticulatory vulnerability in domain-final and carryover coarticulatory reduction in domain-initial; and vowel nasalization can be fine-tuned dynamically.

Some studies investigate phonetic imitation of coarticulatory vowel nasalization (Zellou \& Nielsen, 2016[3]; Zellou, 2017[4]; Zellou, Dahan \& Embick, 2017[5]). Related studies provide the evidence that both speakers and listeners are aware of the process of coarticulatory realization for both communicative and representational accounts of phonetic imitation. The studies on the perceptual evaluation of oral, nasal, and hypernasal vowels in CVC, CVN and NVN words

This research was financially supported by State Language Commission of China (Grant No. YB135-48) and Central Government Special Funds for Northwest Minzu University (Grant No. Yxm2015014). show that listeners' nasal vowel discrimination significantly correlates with produced coarticulation, which does not correlate with vowel nasality ratings. People can make spontaneous modification for coarticulatory nasality to sound like the words they have heard. People's past experience of phonetic imitation has influence on the degree of vowel nasalization.

There appear different views regarding coarticulation in children's speech. Eshghi \& Zajac (2016) [6] examine nasal coarticulation in infants' speech over time at 12, 14, and 18 months of age and draw the conclusion that the development of nasal coarticulation over time can be from a "segmental" level to a "syllabic" level, while Kent (1983) [7] proposes that children's speech is more "segmental" and Nittrouer et al. (1989) [8] suggests that in children's speech syllables are the units of speech production.

In Taiwanese, oral voiced consonants and nasal consonants stay in complementary distribution at the beginning of words: oral voiced consonants only appear before oral vowels, and nasal consonants only appear before nasal vowels (Wang, 2017) [9]. Wang's study shows that Taiwanese nasal vowels are fully nasalized. In Monguor Language, the nasal vowels are also fully nasalized. The Monguor or Tu people are one of the 56 officially recognized ethnic groups in China. The Monguor people live mostly in the Qinghai and Gansu provinces. They speak the Monguor language, which belongs to the family of Mongolic languages but has been heavily influenced by both local Chinese and Tibetan dialects.

\section{METHOD}

\section{A. Source of Corpus}

This study builds a parameter database for nasal vowels of the Monguor speech. The Monguor words with the nasal

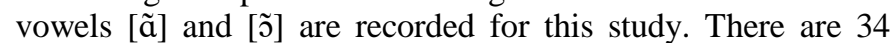
Monguor words which contain the nasal vowel [ã] and 37 Monguor words containing the nasal vowel [õ]. These words consist of monosyllable, disyllable, trisyllable, and quadrisyllable words. The nasal vowels must appear at the end of a syllable. 


\section{B. Speech Signal Collection}

Twelve speakers, 8 male and 4 female, aged from 40 to 65 reads all the selected words. Four speakers serve as teachers in local primary or junior schools. Their speeches belong to Tianzhu dialect (in Gansu province), which is similar to the Huzhu dialect (in Qinghai province). The recording equipment in this study is composed of a Dell Notebook, a Behringer recording microphone, and a sound card of YAMAHA Steinberg. The recording is conducted with a sampling rate $44.1 \mathrm{kHz}$ and resolution ratio 16 bits. The format of recording is saved with *.wav. The sounds are recorded in a recording studio. Each word is read three times by the 12 speakers, so a sample of 36 is gained in the present study.

\section{Measures of Coarticulation}

The parameter of coefficient of dispersion (COD) is applied in this study for the measurement of dispersion. COD is the ratio of the average absolute deviation from the median to the median of the data. The formula of COD is:

$$
\mathrm{COD}=\frac{\sum\left|R_{i}-\bar{R}\right|}{N \times M}
$$

In (1) $\mathrm{R}$ is the ratio of $\mathrm{F} 2$ target (the target value of the second formant) to $\mathrm{F} 2$ onset (the onset value of the second formant); $R_{i}$ is each ratio value; $\bar{R}$ is the mean of all ratio values; $\mathrm{N}$ is the number of the sample; and $\mathrm{M}$ is the median of all ratio values.

Another means of measuring coarticulation in this study is the locus equation, which is a linear regression based on F2 formant transitions from vowel onsets to vowel targets. The F2 value of the onset of a vowel can be plotted on the y-axis, and that of the vowel's target plotted on the x-axis. Accordingly, the two-dimensional data may come into being a regression equation:

$$
\mathrm{y}=\mathrm{kx}+\mathrm{b}
$$

In (2), $\mathrm{k}$ is the slope, and $\mathrm{b}$ is the intercept, which refers to the point where the fitted line crosses the $\mathrm{y}$-axis. $\mathrm{X}$ is independent variable, which refers to the vowel target value, and $y$ is dependent variable, which refers to the vowel onset value. The slope of the fitted line on the plot is a measure of the degree of coarticulation of the consonant by the following vowels.

In this study, COD and locus equation slopes are calculated by putting the values of $\mathrm{F} 2$ target and $\mathrm{F} 2$ onset into SPSS22.0.

\section{Research Questions}

The questions addressed in this study are:

(1) What are the coarticulatory dispersions for the nasal

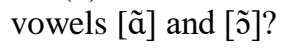

(2) What are the differences in the coarticulatory

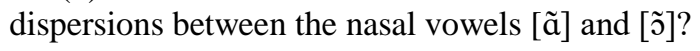

(3) What are the locus equation slopes of the unaspirated stops by the following nasal vowels $[\tilde{a}]$ and $[\tilde{o}]$ ?

\section{RESULTS AND DISCUSSION}

\section{A. Coarticulatory Dispersions for the Nasal Vowels}

In Monguor Language, the vowels /a/ and /o/ can be nasalized before the velar nasal sound $/ \mathrm{y} /$ and will become

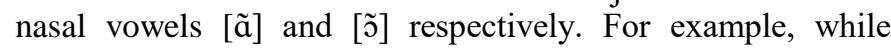
Monguor word "ban" (board) is pronounced as [pan], "bang" (shelf) is pronounced as [pã]; while "janda" (sting) as [tøæntA],

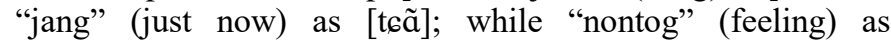
[nont $\left.{ }^{\mathrm{h}} \mathrm{ok}\right]$, "nong" (this year) as [nõ]; while "ghonjasi" (anus) as [Gontcæs]], "ghong" (crow) as [Gõ]. In Monguor language, the

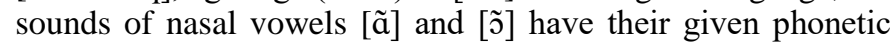
contexts, but they have no the function of distinguishing the meaning of Monguor words.

The examples above show that, in Monguor language, the

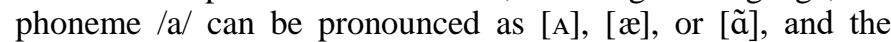

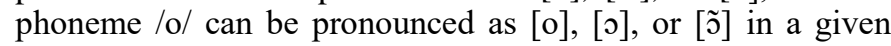
phonetic context. Fig. 1 shows the positions of the first

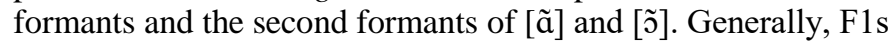

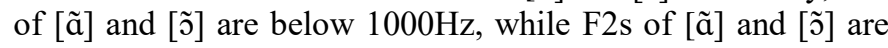
over $1000 \mathrm{~Hz}$ but below $1500 \mathrm{~Hz}$. The upper part of Figure 1 is the contrast of F1 and F2 for [A], [n], and [ã]. The lower part is

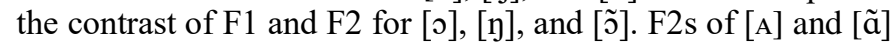
are lower than that of [y], so are F2s of [o] and [o]].

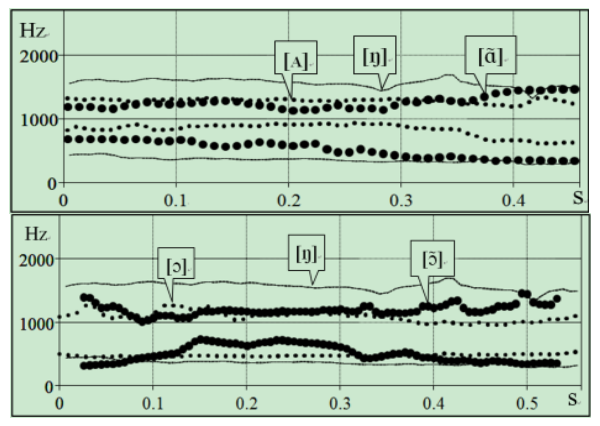

Fig. 1. Formants of $[\tilde{a}]$ and $[\tilde{o}]$

Table I shows the descriptive statistics of dispersions for

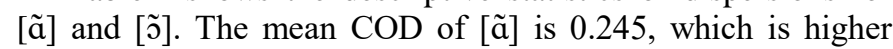

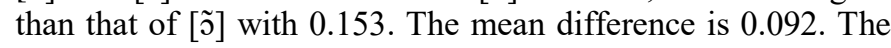
standard deviation (0.115) and the standard error (0.019) for

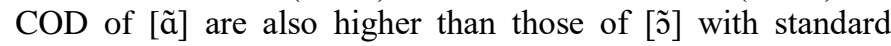
deviation 0.072 and standard error 0.012 respectively. The result shows that the range from the onset value to the target

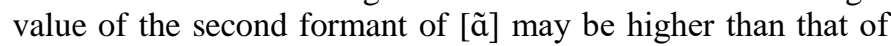
[ว]].

TABLE I. DISPERSIONS FOR THE NASAL VOWELS

\begin{tabular}{|c|c|c|c|c|}
\hline Nasal Vowels & Number & Mean & Std. Deviation & Std. Error Mean \\
\hline$[\tilde{a}]$ & 36 & 0.245 & 0.115 & 0.019 \\
\hline$[\tilde{]}]$ & 36 & 0.153 & 0.072 & 0.012 \\
\hline
\end{tabular}

\section{B. Differences in the Coarticulatory Dispersions}

The descriptive statistics of dispersions show that the mean

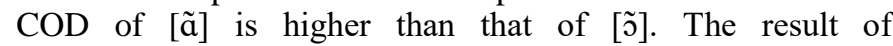
independence $\mathrm{T}$ test validates the conclusion that the 
coarticulatory dispersion of $[\tilde{a}]$ is significantly higher than that of $[\tilde{\jmath}](t=4.050, p=0.000)$. That is to say, different consonants

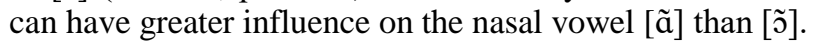

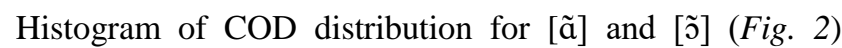

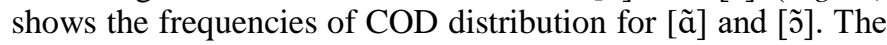
COD distribution for [ [̃] stays mainly between 0.100 and 0.500 . Every one of all the distributing sections, except one with the number 7, has 2 to 4 . The COD distribution for [o] lies mainly between 0.030 and 0.300 . Every one of all the distributing sections, except one with the number 1 , has 2 to 7 .

The reason for higher coarticulatory dispersion of $[\tilde{a}]$ than

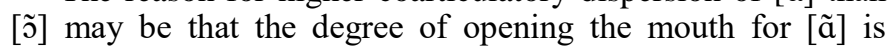

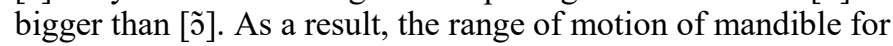

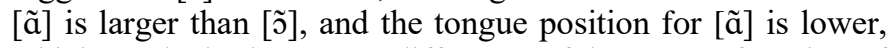
which results in the greater difference of the range of motion of mandible of each speaker for $[\tilde{a}]$.

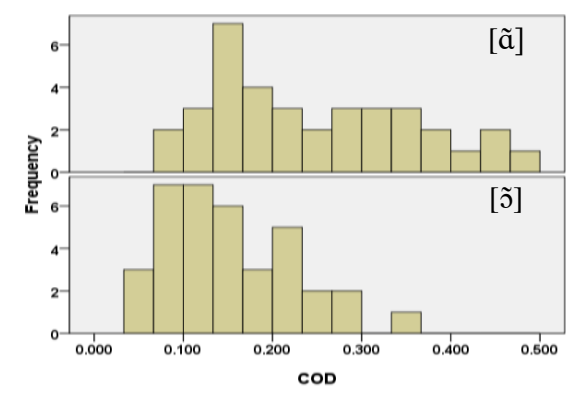

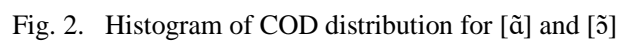

The value of coarticulatory dispersion is relevant to the ratio of $F 2_{\text {target }}$ to $F 2_{\text {onset, }}$ but is irrelevant to the mean of F2. In

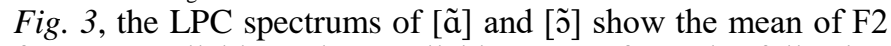
for some syllables. These syllables come from the following Monguor words: "rgang" [zkã] (the top of a mountain), "rghang" [zGã] (power), "sangrji" [sãzțeə] (Great Sage,

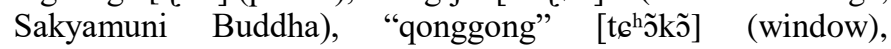
"ghongzor" [Gõtsoz] (chanting leader), "songghu" [s̃̃Gu] (choose, select). The LPC spectrums supply that the mean of

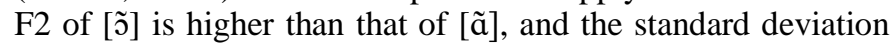

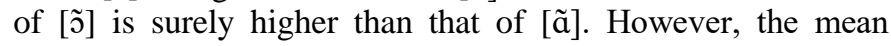
COD of $[\tilde{a}]$ is higher than that of $[\tilde{o}]$.

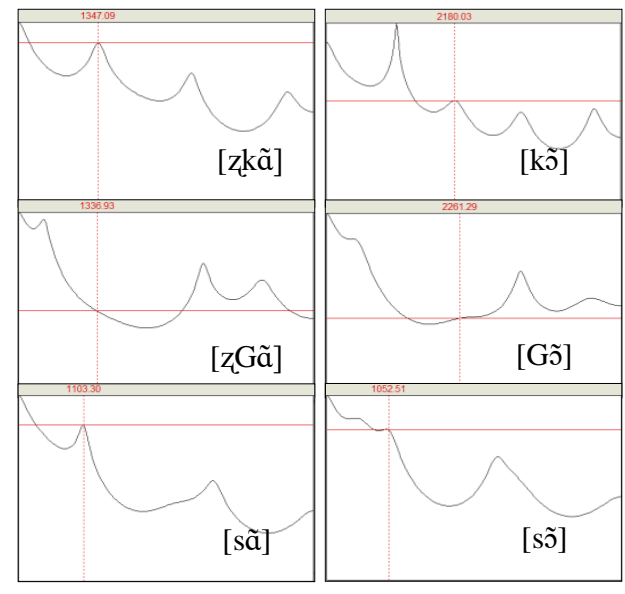

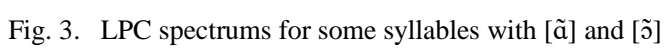

\section{Locus Equation Slopes}

Many researches (e.g. Rentz, \& Anderson, 2016[10]) discuss coarticulation on the locus equation perspective. Some Chinese researchers (e.g. Ran Qibin \& Shi Feng, 2006[11]) have studied the coarticulation in mandarin according to the locus equation slopes of consonants, especially unaspirated stops. This study will discuss the coarticulation according to the locus equation slopes of three unaspirated stops following

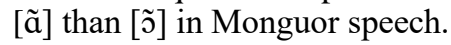

Table II shows that the slope of the bilabial /p/ is 0.846 in Monguor, and the slope of the bilabial $/ \mathrm{p} /$ in mandarin is 0.8 (Ran Qibin \& Shi Feng, 2006) [11], which suggests a high degree of coarticulation for the consonant. $\mathrm{R}$ square is 0.801 (over 0.8), which means that the effect of fit is better. Its locus is $1346 \mathrm{~Hz}$, which is higher than that in mandarin $(900 \mathrm{~Hz})$. The slope of the apical / $t$ / is 0.658 in Monguor, which is higher than that in mandarin (0.58), but is lower than that of the bilabial /p/. The locus of the apical is $1925 \mathrm{~Hz}$, which is higher than that in mandarin $(1714 \mathrm{~Hz})$.

TABLE II. DATA FROM LOCUS EQUATION

\begin{tabular}{|c|c|c|c|c|}
\hline Unaspirated Stops & Locus & Slope & Intercept & $\mathbf{R}^{\mathbf{2}}$ \\
\hline$/ \mathrm{p} /$ & 1346 & 0.846 & 207 & 0.801 \\
\hline$/ \mathrm{t} /$ & 1925 & 0.658 & 658 & 0.862 \\
\hline$/ \mathrm{k} /$ & 333 & 1.093 & -31 & 0.855 \\
\hline
\end{tabular}

In short, the degree of coarticulation for the apical is lower than that of the bilabial in Monguor. When the bilabial is pronounced, lips and the tongue are separate, and have no spatial overlap. That is to say, lips do the action of pronouncing the consonant, and at the same time the tongue do the action of pronouncing the nasal vowels. When the apical is pronounced, both the consonant and nasal vowels use the tongue and have the spatial overlap. As a result, the degree of coarticulation for the apical decreases.

The slope of the velar /t/ is 1.093 in Monguor, which is lower than that in mandarin (1.24). Its slope is much higher than that of the bilabial or the apical in both Monguor and mandarin. Its locus is $333 \mathrm{~Hz}$, which is similar to that in mandarin $(167 \mathrm{~Hz})$. However, the velar locus is obviously not accuracy according to its sound spectrogram. When the velar is pronounced, the tongue body must be involved. The pronunciation of nasal vowels also needs the involvement of the tongue body. Thus, the complete spatial overlap appears on the sound of the velar following nasal vowels.

\section{SUMMARY}

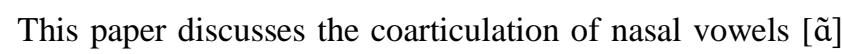
than [̃] in Monguor speech from the point of acoustics. The analysis of statistics shows that the coarticulatory dispersion of

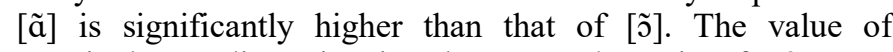
coarticulatory dispersion is relevant to the ratio of $\mathrm{F} 22_{\text {target }}$ to $\mathrm{F} 2$ onset, but is irrelevant to the mean of F2. The locus of the bilabial or apical unaspirated stop can be calculated by means of the locus equation, but not for the velar unaspirated stop. The slope of the velar is the highest, and that of the apical is the lowest in Monguor speech. The result is consistent with studies 
in mandarin. For the acoustic result, this paper has made the analysis from the aspect of sound physiological features.

This study provides a good reference for the study of Monguor phonetics and dialects. It can provide scientific data basis and reliable theoretical basis for the study of Monguor language, thus promoting the study of the languages of the Mongolia branches. Furthermore, this study provides a new research method --- employing the dispersion to measure the degree of coarticulation.

\section{ACKNOWLEDGMENT}

I would like to extend my sincere gratitude to my friend, Zhang Lamaodongzhi, a Tu teacher, and his friends, who have put their considerable time into recording the Monguor words for this paper.

\section{REFERENCES}

[1] T. Cho, "Prosodic boundary strengthening in the phonetics-prosody interface," Language and Linguistics Compass, vol. 10, pp. 120-141, 2016.

[2] T. Cho, D. Kim, and S. Kim, "Prosodically-conditioned fine-tuning of coarticulatory vowel nasalization in English," Journal of Phonetics, vol. 64, pp. 71-89, 2017.
[3] G. Zellou, and K. Nielsen, "Phonetic imitation of coarticulatory vowel nasalization," The Journal of the Acoustical Society of America, vol. 140, pp. 3560-3575, 2016.

[4] G. Zellou, "Individual differences in the production of nasal coarticulation and perceptual compensation," Journal of Phonetics, vol. 61, pp. 13-29, 2017.

[5] G. Zellou, D. Dahan and D. Embick, "Imitation of coarticulatory vowel nasality across words and time," Language, Cognition and Neuroscience, vol. 32, pp. 776-791, 2017.

[6] M. Eshghi and D. J. Zajac, "Nasal coarticulation in normal infants: A physiological analysis," The Journal of the Acoustical Society of America, vol. 139, pp. 2220-2220, 2016.

[7] R. D. Kent, "The segmental organization of speech," in the production of speech, P. F. MacNeilage, Ed. New York: Springer-Verlag, 1983, pp. 57-89.

[8] S. Nittrouer, M. S. Kennedy, and R. S. McGowan, "The emergence of phonetic segments: Evidence from the spectral structure of fricativevowel syllables spoken by children and adults," Journal of Speech and Hearing Research, vol. 32, 120-132, 1989.

[9] S. F. Wang, "A Dispersion-Theoretic Account of Taiwanese CV phonotactics," Proceedings of the Annual Meetings on Phonology, vol. 4, 2017.

[10] B. Rentz, and V. Anderson, "The Pohnpeian stop contrast between laminal alveolars and apical dentals involves differences in VOT and F2 locus equation intercepts," The Journal of the Acoustical Society of America, vol. 140, pp. 3111-3111, 2016.

[11] Q. B. Ran \& F. Shi, "The study on the coarticulation of unaspirated stops in mandarin from the point of locus equation," Nankai Linguistics, vol. 162, pp. 45-54, 2006. (in Chinese) 